\title{
Uma antropologia que dança: algumas notas sobre paisagens de conceitos em Anna Tsing
}

An anthropology that dances: some notes on Anna Tsing's landscapes of concepts

\section{Gabriel Holliver}

\section{(2) OpenEdition}

12 Journals

Edição electrónica

URL: http://journals.openedition.org/aa/6653

DOI: $10.4000 / a a .6653$

ISSN: 2357-738X

Editora

Programa de Pós-Graduação em Antropologia Social (UnB)

\section{Edição impressa}

Paginação: 189-202

ISSN: 0102-4302

Refêrencia eletrónica

Gabriel Holliver, «Uma antropologia que dança: algumas notas sobre paisagens de conceitos em Anna Tsing», Anuário Antropológico [Online], v.45 n.3 | 2020, posto online no dia 16 setembro 2020, consultado o 27 abril 2021. URL: http://journals.openedition.org/aa/6653 ; DOI: https://doi.org/ $10.4000 / a a .6653$

\section{(c) $(1)(9)$}

Anuário Antropológico is licensed under a Creative Commons Atribuição-Uso Não-Comercial-Proibição de realização de Obras Derivadas 4.0 International. 


\section{Uma antropologia que dança: algumas notas sobre paisagens de conceitos em Anna Tsing}

An anthropology that dances: some notes on Anna Tsing's landscapes of concepts

DOI: https://doi.org/10.4000/aa.6653

\section{Gabriel Holliver • Universidade Federal do Rio de Janeiro - Brasil}

Doutorando em Antropologia Social pelo Programa de Pós-Graduação do Museu Nacional da Universidade Federal do Rio de Janeiro. Mestre pela mesma instituição e graduado em Ciências Sociais pela PUC-Rio. Realiza desde 2015 pesquisa com "agricultores experimentadores" no semiárido brasileiro, com ênfase em conhecimento tradicional, sistemas agrícolas e relações multiespécies.

O presente ensaio busca tecer alguns comentários acerca dos artigos presentes no livro Viver nas ruínas: paisagens multiespécies no Antropoceno (2019), de Anna Tsing. Ao oferecer um panorama dos principais conceitos e linhas de força que atravessam o pensamento da autora, por meio de um percurso entre fungos, relações multiespecíficas e plantations, discuto as principais contribuições de sua obra para a teoria antropológica bem como a importância dos conceitos de paisagem, assembleia e coordenação para as técnicas de descrição etnográfica no Antropoceno. Em paralelo, apresento algumas críticas de Tsing à reificação do excepcionalismo humano na antropologia e esboço possíveis diálogos entre suas reflexões e a teoria social contemporânea.

Anna Tsing. Relações multiespécies. Teoria antropológica. Paisagem. Assembleia.
This essay is a commentary on the Brazilian collection of papers by Anna Tsing, presented in the book Viver nas ruínas: paisagens multiespécies no Antropoceno (2019). By offering an overview of the main concepts and lines of strength that cross the author's thought, through a path among fungi, multispecies relations, and plantations, I discuss the contributions of Tsing's work to the anthropological theory, as well as the importance of the concepts of landscape, assembly, and coordination to the techniques of ethnographic description in the Anthropocene. In parallel, I present some of Tsing's critiques on the reification of the human exceptionalism in anthropology, and finally possible dialogues between the author's thinking and the contemporary social theory.

Anna Tsing. Multispecies relations. Anthropological theory. Landscape. Assembly. 
Em maio de 2019, durante a VII Reunião de Antropologia da Ciência e Tecnologia (ReACT), a antropologia brasileira se viu brindada com a publicação do primeiro livro em português de Anna Lowenhaupt Tsing. O inédito Viver nas ruínas: paisagens multiespécies no Antropoceno (2019), organizado por Thiago Mota Cardoso e Rafael Victorino Devos, publicado pela editora IEB Mil Folhas, foi traduzido por uma equipe multidisciplinar, em um projeto coletivo que envolveu nove pesquisadores de diferentes disciplinas e em diferentes estágios de formação.

A edição oferece uma coletânea de dez artigos da autora, publicados ao longo de sete anos (entre 2011 e 2017), através dos quais é possível obter um panorama abrangente de seu pensamento. Dividido em três partes, podemos sugerir, apenas para fins de uma exposição sistemática, que cada conjunto procura tratar mais detidamente sobre uma questão particular. Se os primeiros artigos $(1,2,3)$ se debruçam especialmente sobre fungos - em especial o cogumelo matsutake (Tricholoma nauseosum), protagonista e tema de seu livro de 2015, O cogumelo no fim do mundo: sobre a possibilidade de vida nas ruinas do capitalismo -, os quatro artigos seguintes $(4,5,6,7)$ lançam um olhar atento sobre a crítica de Tsing ao excepcionalismo humano que atravessa a teoria antropológica e as técnicas de descrição etnográfica; enquanto os três últimos $(8,9,10)$ se dedicam sobretudo ao tema do Antropoceno, quando a autora se engaja numa discussão sobre o termo, abordando tanto movimentos de destruição quanto de regeneração.

Mas este esquema é ainda muito rígido para os padrões de Anna Tsing, pois sua labiríntica reflexão não permite estabilizar nem reduzir suas questões a apenas três grandes temas. Mais do que tentar realizar uma espécie de resumo bem elaborado dos artigos presentes em seu necessário livro, me parece mais oportuno oferecer um panorama dos principais conceitos e linhas de força que atravessam seu pensamento, na tentativa de trazer à frente da cena os múltiplos elementos da paisagem conceitual construída pela autora.

Antes de efetivamente adentrar nos mundos para os quais somos levados através de Anna Tsing, um comentário inicial parece importante para evitar possíveis equívocos acerca de sua obra. Uma leitura desatenta do título do livro Viver nas ruinas: paisagens multiespécies no Antropoceno poderia sugerir se tratar de uma antropologia da destruição ou da morte, apenas pelo fato de lidar com ruínas e paisagens devastadas. Nada mais distante que isso, pois embora Tsing esteja atenta ao problema de habitar o Antropoceno e às extinções que continuamente se proliferam pela biosfera, desfazendo mundos por toda parte do globo terrestre, o brilho de seus trabalhos acena para os meios e modos de ocupar as ruínas, recuperar paisagens e habitar lugares desmantelados. Em sua obra, destroços e regeneração, extinção e sobrevivência, poluição e adaptação, demolição e reconstrução são colocados lado a lado (2019, p. 162). Implícita a essa paisagem conceitual se constitui um projeto de ecologia política, que reside essencialmente em "aprender a ocupar até os espaços mais degradados da vida na Terra” (2019, p. 87), de modo que se fosse necessário classificar sua antropologia, seria melhor afirmar que se trata sobretudo de um estudo da composição da vida, nas mais distintas possibilidades de existência. 
Esta incansável fé e afirmação da vida perante a morte encontra ressonância em outro traço marcante no pensamento de Anna Tsing, que retorna, por outros meios, ao problema da descrição etnográfica posto pelos pós-modernos (Clifford; Marcus, 1986). Ao contrário destes, que colocavam questões acerca do caráter fictício - no sentido de artificialmente fabricado - na retórica e poética antropológica, há por parte da autora uma paixão e defesa da etnografia, segundo ela, o "dom mais importante de nossa disciplina” (2019, p. 92). Ao assumir o aspecto literário como estratégia de escrita e levá-lo até as últimas consequências, por meio do que chama de "art of noticing" (2019, p. 18), experimenta um estilo de descrição etnográfica que explicitamente se inspira em autores de ficção científica ${ }^{1}(2019$, p. 64) para criar dispositivos textuais e afetar imaginativamente seus leitores. Se Tsing descreve as atividades dos forrageadores como uma espécie de dança cinética (2019, p. 27), não parece descabido falar de sua antropologia como uma ciência que dança (Stengers, 2016). Brincando e assumindo os riscos de tal empreitada, ao mobilizar seu material, baila entre o humano e o não humano, o local e o global, o tradicional e o moderno/científico e, sem respeitar as fronteiras estabelecidas pelas divisões disciplinares, habita ao mesmo tempo as duas culturas (Snow, 1959). Voltando-se para a ambivalência das fricções sem a pretensão de oferecer uma síntese estabilizada, evita qualquer tipo de redução ou classificação englobante $a$ priori, seja a sociedade ou a espécie.

O objetivo de fugir do excepcionalismo humano leva sua etnografia a descrever o mundo de outros organismos, e ao mesmo tempo que segue cientistas, segue também camponeses, catadores de cogumelos apaixonados, todo e qualquer ponto de vista situado (Haraway, 1995) que possa ajudá-la a descortinar o mundo de outros organismos (2019, p. 44). Atenta não apenas às dinâmicas dos lugares, Tsing traça as redes de conexões globais que eles estabelecem, e simultaneamente narra histórias particulares, disserta sobre capitalismo, sistemas de parentesco e questões de gênero. Seu método de “descrição crítica” busca entrelaçar relações entre humanos e não humanos através de múltiplas escalas não aninhadas na paisagem (2019, p. 66), o que compreende tanto interação e modelagem recíproca quanto o que chama de "design não intencional".

Marilyn Strathern figura como principal referência na coleção de artigos do livro: personagem com maior número de citações, é inclusive homenageada em um dos textos. Há ainda outros autores que contribuem para sua descrição crítica multiespécie, e em determinado momento a própria Tsing explicita suas afinidades teóricas. Como ela afirma, as companhias mais proeminentes de seu pensamento podem ser encontradas:

i) no comprometimento de Donna Haraway (2007) em reaprender os humanos como uma "espécie companheira" entre outras; ii) na teoria do ator-rede de Bruno Latour (2005), que abriu as portas para as teorias do social em que os não humanos desempenham um papel central; iii) na insistência de Tim Ingold (2011) de que prestar atenção na vida em movimento renova as possibilidades de uma antropologia mais que humana; e iv) na afirmação
1 Outra autora cuja ressonância se faz presente é Donna Haraway - ver sua sugestão de nomear a atual catástrofe ecológica em curso a partir de um personagem de H.P. Lovecraft (Haraway, 2016); uma reflexão acerca do rendimento teórico das figuras de ficção científica para a atual conjuntura pode ser encontrada em: Haraway, 1992. Em coletânea recente organizada por Tsing em colaboração com outros pesquisadores, são estabelecidos diálogos transversais entre autores de diversos campos de investigação a partir das imagens correntes na ficção científica de monstros e fantasmas (Tsing et al., 2017). 
de Eduardo Kohn (2013) de que as florestas "pensam", isto é, que fazem um trabalho de representação (Tsing, 2019, p. 121-122).

Outro autor que, sem dúvida, ajuda Anna Tsing a pensar, ainda que nem sempre por meio de convergências, é Eduardo Viveiros de Castro. Descrito como "empolgante e polêmico" (2019, p. 216), em vários artigos do livro seu pensamento é acionado. $\mathrm{O}$ conceito de "anarquia ontológica" lhe é útil para infletir a história natural antropocêntrica e incluir aqueles atores "menores" através de uma teoria anticolonial que nos permite vislumbrar outros mundos possíveis (2019, p. 217). Porém, em outros momentos, o próprio se torna alvo de acusações de antropocentrismo, ao lado de outros pesquisadores que a autora inclui como pertencentes à virada ontológica, corrente teórica que demonstra admiração e respeito, sem deixar de manter divergências. Isso porque, segundo Tsing, na medida que os não humanos só são trazidos à existência através da perspectiva humana, estes trabalhos continuariam a reificar o excepcionalismo antropocêntrico, não permitindo a emergência de mundos e paisagens mais que humanas. De acordo com a autora, nestas abordagens as ontologias nunca se tocam, enquanto sua preocupação reside sobretudo no encontro, quando ocorre o toque ${ }^{2}$ (2019, p. 262).Porém, me parece que alguns trabalhos clássicos da etnologia amazônica ajudariam a desfazer tal (in)compreensão. Para citar alguns exemplos, o encontro de humanos e porcos descrito por Tânia Stolze Lima (1996) no artigo fundante do perspectivismo ameríndio, no qual a autora rejeita qualquer definição a priori ou classificação englobante, sendo a posição definida sobretudo no ato do encontro, ainda que neste caso a questão seja sobretudo a humanidade em seu sentido performativo, não natural; o trabalho de William Balée (2013), em que o autor nos apresenta a floresta amazônica como resultado de uma geobricolagem milenar, onde a horticultura e o manejo, tanto direto quanto indireto, geraram uma floresta antropogênica (nos termos de Tsing, uma floresta essencialmente moldada por perturbações); além da recente contribuição de Mauro Almeida (2013) para as reflexões em torno da virada ontológica, cujo foco é sobretudo o que se passa quando as ontologias se encontram, seja por meio de conflitos, guerras ou acordos pragmáticos; e, respectivamente, como determinadas visões de mundo orientam as interações estabelecidas com a vida mais que humana nos encontros pragmáticos do cotidiano.

Matsutake, o fungo estudado por Tsing, é dotado de uma complexidade singular. Característico da culinária japonesa, existindo como expressão da cultura local, é um cogumelo selvagem que, resistente à domesticação e ao cultivo, apenas pode ser coletado em locais onde gosta de habitar, a saber, "florestas perturbadas" pelo manejo humano. Este, por volta dos anos de 1970, veio se tornar uma raridade ao ponto de converter-se no cogumelo mais caro do mundo, quando, por uma série de movimentos de modernização no Japão, as florestas locais deixaram de ser manejadas pelas populações nativas. Seguindo pessoas apaixonadas por
2 Uma exposição mais sistemática das divergências da autora perante a virada ontológica pode ser encontrada em Tsing (2018). No seu argumento, uma abordagem focada exclusivamente na experiência humana corre o risco de perder de vista a própria interferência de outros seres na própria socialidade humana. Por oposto, ignorar o que outras ontologias têm a dizer sobre os acontecimentos em uma abordagem essencialmente biocêntrica, isto é, que leve em conta apenas os discursos promovidos pelas ciências naturais, igualmente reduziria a capacidade de análise (2018a, p. 234-235). 
este cogumelo, Tsing cartografa tanto heterogêneos tipos de relação humana com o matsutake quanto diferentes interações do fungo em paisagens multiespécies (2019, p. 29).

A comparabilidade tão evitada pela descrição modernista e retomada por Marilyn Strathern $(1987,1988,2014)$ permite Tsing levar tal técnica para outros rumos, comparando espécies de mundos aparentemente incompatíveis. A partir da especulação do ponto de vista de um esporo, ela aponta o que humanos podem aprender com seu modo de existência. Neste movimento que desorienta leituras convencionais, novas percepções disruptivas emergem, permitindo a emergência de um gênero estranho de conhecimento. Como afirma a autora, "muitas vezes é a própria incompatibilidade das unidades sendo comparadas que ilumina o relacionamento entre ferramentas e objetos de pesquisa” (2019, p. 70).

O relato especulativo do ponto de vista de um esporo de matsutake, em uma experiência que mistura etnografia e história natural, nos possibilita ir além da ideia de agência individual num crítico desarranjamento do conceito de liberdade, tão basilar para autores como John Locke e Immanuel Locke. A suposição de que nós dispomos de uma autônoma liberdade individual, enquanto os outros seres vivos apenas reagem aos impulsos da natureza, é implodida quando Tsing nos conduz à compreensão de que nossa existência se constitui por meio da composição de "agregados multiespécies" (2019, p. 73). Com efeito, nosso intestino está para as bactérias intestinais assim como as árvores estão para os fungos e, em ambos os casos, há seres diferentes que se associam para se tornarem o que Haraway chama de "companheiros de mesa" (2007). De modo que nossa liberdade depende, de maneira incontornável, de uma adequada articulação de outras forças que compõem nosso organismo em "trajetórias interativas contínuas em crescimento indeterminado” (2019, p. 75). A partir de um ponto de vista fúngico, nossa autonomia é confrontada com a indeterminação que faz a vida acontecer em suas múltiplas escalas, pois, como afirma Tsing, a presunção de que nós somos seres livres, em contraste com outras formas de vida, é uma ilusão, "na maioria das vezes, fazemos o melhor que podemos com as circunstâncias que encontramos, justamente como outras criaturas o fazem"3 (2019, p. 124).Uma vez que as ideias de indeterminação e do agregado de múltiplas trajetórias têm efeito para compreensão dos corpos fúngico e humano, estes mesmos princípios podem se estender para texturas de paisagens mais abrangentes, em outras escalas, até o nível mais global do planeta Terra, se tratamos o último como uma espécie de superorganismo (Lovelock, 1997), forjado a partir de agregados multiespécies. Aqui o conceito de "assembleias" cumpre uma importante função no aparato técnico para a descrição crítica, pois ele oferece uma lente favorável para o analista perceber o comportamento e a composição de diferentes manifestações da vida no mundo.

Embora a relação do conceito "assembleia" (tradução de assemblage) esteja fortemente marcada pela filosofia de Deleuze e Guattari, o uso que Tsing faz do termo provém sobretudo da ecologia da paisagem, cujo objetivo reside em registrar relacionalidades de "organismos que podem ser encontrados juntos e agrupados em um lugar" (2019, p. 17). Desse modo, o social não pode mais ser
3 Tanto na história profunda da Terra, quanto no tempo de vida dos organismos que nela habitam, a ideia de coevolução formulada por Haraway, em seu Manifesto das Espécies de Companhia (2003), evidencia o fato de que os indivíduos nunca atuam em singularidade. As interações entre os corpos geram como consequência, alterações ao mesmo tempo biológicas e culturais. 0 exemplo da domesticação dos cães oferecido pela autora ilustra como o processo de adaptação ocorre sempre em mutualidade. Aqui, a indeterminação é a regra, "o relacionamento é multiforme, em jogo, inacabado e consequente" (Haraway, 2003, p. 12).

4 Tal como "friction" poderia ser melhor traduzido por “atrito" (ver Tsing, 2018b), os sentidos que as ideias de "composição" e "agenciamento" carregam, ofereceriam outras possibilidades de tradução que evitariam um possível equívoco em associar as ideias que a autora pretende transmitir ao nosso vocabulário das ciências humanas de representação política, ou mesmo, com o parlamento das coisas proposto por Bruno Latour. Porém, na medida em que se trata de um ensaio bibliográfico, decidimos por manter o termo tal como os tradutores optaram no livro. Em outra ocasião, em resenha do livro de 2015, Cardoso (2019) em consonância com a programa da autora de diálogo com as ciências biológicas, para se referir ao conceito, optou pela mesma tradução do termo, tal como na ecologia da paisagem. 
tecido por distinções entre humanos e não humanos, ou entre cultura e natureza, mas é "produzido em relações intricadas com outros significantes" (2019, p. 119). Se estudar seres com quem não podemos estabelecer diálogos gera um problema técnico de comunicação, uma alternativa para o impasse pode ser encontrada tanto na observação das assembleias, isto é, aquilo que encontramos reunidos numa paisagem quanto nas formas. Podemos, por exemplo, perceber no corpo de uma árvore sua biografia: ali encontramos materializadas historicamente suas relações sociais e, lembremos, a morfologia sempre foi um tema caro para nós, antropólogos.

As assembleias não necessariamente devem incluir os humanos em suas relações, porém, uma vez que estes se disseminaram por todo o planeta, é pouco provável encontrar algum local onde não exerçam nenhum papel ativo, ainda que de maneira indireta ${ }^{5}$. O que por sua vez, não significa que os humanos estejam sempre no controle, pois, "os humanos são parte da história, mas humanos não fazem a história" (2019, p. 149). Para descrição crítica, todos os movimentos e trajetórias devem importar, as diferentes histórias devem ser trazidas à superfície em conjunto. Assim, "os humanos seriam um entre vários agentes históricos" (2019, p. 130), em uma paisagem sempre dinâmica, tecida em um design não intencional e sem administração central, na qual a única ordem é a contingência e a indeterminação quanto a seu futuro. Com efeito, para cartografar assembleias, é preciso mobilizar ferramentas teóricas capazes de animar o material e registrar tanto encontros quanto relações. É necessário atravessar escalas, emaranhar trajetórias, misturar os elementos e projetos de paisagem, fazendo eles dançarem. A proposta de Donna Haraway é um exemplo que lhe serve como inspiração, pois, ao empilhar histórias sobre histórias não convergentes, adicionando camadas de contexto sobre contexto, o material se complexifica, confunde, não permite uma totalização, mas permanece aberto a ser explorado e recodificado a cada movimento. Nesse sentido, a falta de uma síntese totalizadora é positiva, pois, "quando as peças não se encaixam perfeitamente, uma variedade de maneiras de se conhecer pode ser útil” (2019, p. 239). Para Tsing, não basta tratar os não humanos mantendo a base do compasso fixa nos humanos, de modo que o analista deve se manter igualmente atento às interações nas quais os humanos não exercem papel ativo.

Outro conceito importante para Anna Tsing, derivado da ideia de assembleia e formulado na companhia de Elaine Gan, é “coordenação” (ver: Gan, 2016; Gan; Tsing, 2018). Ele pretende ser útil para observar múltiplas ações e emergências, sem que necessariamente haja comunicação entre as partes, possibilitando reconhecer como múltiplas trajetórias, ainda que agindo de maneira independente e em temporalidades distintas, se articulam em uma sintonização particular. Humanos e não humanos podem não se associar diretamente e ainda assim gerar paisagens em companhia. Tais coordenações podem ou não ser duradouras, pois na multiplicidade de movimentos, a estrutura está permanentemente aberta a transformações.

Ao estabelecer uma crítica tanto aos estudos de ciência e tecnologia quanto às pesquisas junto a populações tradicionais que lidam com interação entre humanos
5 Como afirmam Van Dooren e Rose ao formularem uma proposta de contar histórias de mundos animistas que esteja atenta para ouvir e oferecer um testemunho digno daqueles cujas histórias nos propomos contar: "Enquanto uma etografia tende a começar com, a ser provocada por, formas de vida outras que humana, a abertura desses relatos, traz inevitavelmente, humanos para o quadro" [tradução nossa] (2016, p. 86). 
e animais, Tsing identifica um mesmo princípio de precaução nas duas abordagens. Em ambos os casos, os pesquisadores se restringem às definições de seus interlocutores e se contentam em apenas relatar o que estes afirmam, sem buscar por si mesmos observar e conhecer o material (2019, p. 144-147). Neste momento, Tsing remete a autores com orientações teóricas bastante diversas para afirmar que nenhum deles consegue, de fato, escapar da primazia da perspectiva humana. Deborah Bird Rose, Donna Haraway, Thom Van Dooren e Jacques Derrida são acusados de capturar o animal apenas como resposta aos estímulos humanos. Já Eduardo Viveiros de Castro e Rane Willerslev orientariam suas preocupações sobretudo às abstrações cosmológicas, o que abriria uma lacuna no que concerne às descrições da vida animista propriamente vivida. No intuito de evitar contaminar o objeto com apontamentos e especulações próprias, tal restrição ao contrário de conferir mais integridade ao material, reduziria as possibilidades de análise.

A questão colocada está longe de uma solução definitiva. O debate em torno da geração de conhecimentos acerca das socialidades mais que humanas parece longe de uma estabilização provisória (para outra perspectiva desta crítica, ver: Stépanoff, 2017). Dito isso, algumas considerações sobre o atual impasse são oportunas. Se adotarmos a definição de antropologia como "ciência da autodeterminação ontológica dos povos do mundo', e seu corolário, a saber: que a missão da disciplina é promover a 'descolonização permanente do pensamento"' (Viveiros de Castro, 2002, 2003, 2009), é necessário que tal axioma se traduza em uma prática comprometida, em primeiro lugar, com uma ciência social do observado (Lévi-Strauss, 1958[1975], p. 404). Afinal, lembremos, nossa disciplina surge de uma aliança irrevogável com outras linguagens estranhas (Clastres, 1968), cujo vigor reside sobretudo na possibilidade de ouvir e aprender com as histórias maravilhosas que os outros têm a nos contar'.

Por outro lado, parece que Anna Tsing pretende realçar o fato de que nós, praticantes da antropologia, continuamos mantendo o dualismo entre natureza e cultura mesmo quando temos a pretensão de dissolvê-lo em nossas descrições. Uma paisagem é sempre composta de um agregado de vidas que interagem em agrupamentos abertos, nos quais, na maior parte dos casos, temos os humanos dentre uma multiplicidade de seres. Explicitar essas relações exige que nos distanciemos dos binarismos, quer dizer, não basta apenas conceder agência aos não humanos; é preciso preencher a paisagem com toda vida que ela contém, retirando o humano de seu altar monárquico sobre uma natureza subjugada.

É verdade que este trabalho já vem sendo realizado através de outras abordagens, como a ANT (Actor-Network Theory, ou Teoria Ator-Rede), a malha proposta por Tim Ingold, além da já mencionada virada ontológica. Porém, embora os estudos multiespécies se beneficiem de todo esse conhecimento acumulado, há um traço distintivo nesse tratamento do material. Além do estilo descritivo próprio e inovador que, "rico em anedotas, metáforas e figurações" (Van Dooren, Kirksey, Munster, 2016, p. 45), pretende atrair o leitor para uma proximidade ética etoecológica com os eventos narrados (ver: Rose, 2013; Van Dooren; Rose, 2016), o centro da análise reside na própria vida mais que humana - o matsutake para
6 Dado que a antropologia é por definição antropocêntrica, fato expresso em seu prefixo antropos, os movimentos de recusa a esta tradição devem vir acompanhados de uma atenção para que nesta manobra, os discursos da disciplina não se tornem etnocêntricos, uma vez que, de maneira inevitável, o ponto de vista é sempre humano, seja ele o nativo indígena, o cientista natural ou mesmo o antropólogo que relata histórias e escreve monografias. 
Anna Tsing, abutres para Thom Van Dooren, insetos para Hugh Raffles, dentre outros inumeráveis exemplos. Aqui, não se trata de focalizar relações dialógicas entre humanos e determinados seres mais que humanos, mas de "concentrar-se nas multidões de agentes animados que fazem com que eles estejam em meio a relações emaranhadas" (Dooren; Kirksey; Munster, 2016, p. 42). As questões que Raffles procura responder em seu tratado sobre insetos são elucidativas desta perspectiva de análise: "Quem são eles, esses seres tão diferentes de nós e um do outro? O que eles fazem? Que mundos eles fazem? O que fazemos deles? Como vivemos com eles? Como poderíamos viver com eles de maneira diferente?" [tradução nossa] (Raffles, 2010)7.

Qualquer paisagem é sempre resultado de sucessivos movimentos, uma "biografia comunitariamente entrecruzada" (2019, p. 82), que aponta para diferentes futuros possíveis. Para descrevê-la, as relações existentes devem ser contadas não por díades, mas por meio dos contornos, histórias e sedimentos de atividades que compõem tal emaranhado coordenado (2019, p. 149). Como bem lembra o poema de Alberto Caeiro, "Natureza não existe/ Que há montes, vales, planícies,/ Que há árvores, flores, ervas,/ Que há rios e pedras,/ Mas que não há um todo a que isso pertença,/ Que um conjunto real e verdadeiro/ É uma doença das nossas ideias" (Pessoa, 1946). Aqui, o interessante não é a marche da história, mas as justaposições e entrecruzamentos de diversas histórias reunidas constituindo assembleias.

Se no século XX a teoria hegemônica presente na biologia foi o neodarwinismo, com a ideia de unidades autônomas e desenvolvimento por melhores adaptações evolutivas ao ambiente, no século XXI têm sido cada vez mais presentes abordagens que defendem o fato de organismos individuais não se constituírem como seres autônomos, "é como se todos os organismos precisassem de outros organismos para seu próprio desenvolvimento, e em muitos casos, organismos de outras espécies" (2019, p. 97). Desse modo, em crescente na biologia, o mutualismo deixa de ser compreendido como um acontecimento causal para algo necessário no processo evolutivo (ver Margulis, 2001; Gilbert; Sapp; Tauber, 2012). Com efeito, "a evolução seleciona relacionamentos, não unidades individuais, em qualquer escala” (2019, p. 97). Assim, a investigação volta-se para as relacionalidades, isto é, processos dinâmicos de associação, "evento é a palavra" (Strathern, 2016, p. 245). A unidade de análise não mais repousa sobre o indivíduo, mas reside especialmente em uma abordagem preocupada com registro e descrição de vínculos associativos entre os respectivos atores.

Prestar atenção a esses relacionamentos permite incluir na história diferentes processos de gerações de vida. Isso é especialmente importante no contexto atual, pois em nenhum outro momento da história da humanidade, a vida tal como o homo sapiens conheceu esteve tão vulnerável quanto agora. Eis outra questão cara a Tsing: a ameaça à habitabilidade provocada pela intrusão de uma nova época geológica, o Antropoceno. Continuamos no terreno mais que humano, pois, "se queremos saber algo sobre mudança ambiental, precisamos saber sobre os mundos sociais que outras espécies ajudam a construir" (2019, p. 128).
7 Há ainda em Tsing, mas não apenas, outro contraste em relação a ANT importante de sublinhar: nos estudos multiespécies, o paradigma não mais reside no estudo de controvérsias; e diferente da investigação da ciência em ação (ver, por exemplo: Callon, 1986), o uso do material científico é quase sempre mobilizado já em seu estado estabilizado. Como a própria autora afirma: "assim como Strathern confia em etnógrafos da Melanésia para seus experimentos reflexivos, eu confio em micologistas e ecologistas para os meus" (Tsing, 2019, p. 68). 
O Antropoceno é uma catástrofe global, mas experimentado de modo diferente em cada local. Esta é a máxima do conceito antropológico de Antropoceno que Tsing propõe por "Antropoceno fragmentado”. Se os humanos no Japão e no Brasil sentem os efeitos das mudanças climáticas de modo distinto, o mesmo se passa com as outras espécies ameaçadas pelas atuais transformações biogeoquímicas da Terra, de modo que é preciso verificar como elas reagem diferentemente em distintos lugares aos efeitos da atual ecologia de "proliferação de morte" (2019, p. 112). Uma época geológica só pode ser global, pois diz respeito a movimentos que se fazem presentes em toda a biota terrestre, mas se apresenta através de sucessivas variações que diferem em cada contexto.

Novamente as ambivalências de Marilyn Strathern são boas para pensar. Ao lidar com um material que não se encaixa perfeitamente, ela "nos obriga a considerar a multiplicidade através de escalas conflitantes, com suas conexões e desconexões" (2019, p. 207). O adjetivo que Tsing acrescenta ao Antropoceno pretende explicitar sua complexidade. Parafraseando Strathern, ela afirma, ele é "menos que um, mais que muitos" (2019, p. 221), pois se o humano não detém o controle sobre toda a extensão da superfície planetária, há algo que se multiplica em todos os lugares ${ }^{8}$. Nesse sentido, uma abordagem que pretenda dar conta desse acontecimento, deve dançar com as fricções e, ao mesmo tempo que cartografar histórias particulares, realizar conexões amplas (2019, p. 238). Se o Antropoceno sugere uma "história universal negativa" (Chakrabarty, 2009), a contribuição dos antropólogos pode estar em introduzir "desigualdade, história e especificidade cultural” (2019, p. 247). A antropologia se coloca como um saber particularmente propício para introduzir tal inflexão, pois ao compartilhar o prefixo antropos com Antropoceno, se diferencia de sua unidade na medida em que, nas palavras da autora, "rasga seu manto em perspectivas fragmentadas e modos de vida" (2019, p. 204) $)^{9}$.

Para pensar o Antropoceno, Tsing sugere a imagem da plantation como objeto privilegiado, expandindo seu uso para além dos sistemas agrícolas. Ela é, ao mesmo tempo, signo colonial e avatar do Homem da destruição, máquina que, ao se proliferar, carrega o princípio da unidade para as paisagens que ocupa, mas que necessita intrinsecamente da diversidade contida em seu exterior para expandir-se e acumular valor. Um sistema de produção que se alastra como um modelo estabilizado e aplicável em diferentes escalas (Viveiros de Castro, 2019), cuja replicação é possível sem que suas propriedades elementares se percam. Em um sentido mais amplo, a plantation pode ser compreendida como "ecologias simplificadas projetadas para criar ativos para futuros investimentos” (2019, p. 226).

É a capacidade de estabelecer cortes nas relações que permite a plantation manter seu design estabilizado. Nos sistemas agrícolas de monocultura, as plantas são destituídas de seus respectivos mundos, perdem suas companhias substituídas por fertilizantes químicos e minerais e, isoladas, as paisagens se simplificam (2019, p. 44). Tomemos, por exemplo, a cana-de-açúcar, conforme seu uso pelo
8 "As mudanças que ocorrem hoje em dia são tão grandes que eu encontraria indícios delas se fosse para qualquer lugar, desde que recebesse orientação adequada" (Kolbert, 2015, p. 11).

9 Como sugeriu Latour (2018) em um diálogo com Tsing, o atual "presente venenoso", sugere um impulso para repensar o antropos e tornar a disciplina antropológica relevante no campo científico, na medida em que esta pensa a crise ambiental gerada pelo seu próprio objeto. 
sistema colonial europeu de produção: no Novo Mundo, a espécie vivia isolada geneticamente, sem espécies companheiras ou pragas. A escravização e a migração forçada de populações nativas da África também criou entre os humanos um abismo nas relações sociais. Ambos transplantados, estavam escravos e cana-de-açúcar desterritorializados, isolados de suas respectivas morfologias sociais anteriores (2019, p. 184). Segundo Tsing, para que a plantation possa se instalar, “é preciso criar terra nullius, [...] os emaranhamentos nativos, humanos e não humanos, devem ser extintos, refazer a paisagem é uma maneira de se livrar deles” (2019, p. 186). Foi ela a primeira forma social de agricultura voltada exclusivamente para o comércio, e seu modelo, que tornava a mão-de-obra escrava não apenas uma realidade como condição necessária para sua existência, ao permitir paralelamente a acumulação primitiva e a emergência do capitalismo, foi posteriormente levado para as fábricas, mantendo neste regime a mão-de-obra de igual modo intercambiável e substituível ${ }^{10}$.

Diferente do cuidado e do amor conservado pela agricultura tradicional, a plantation desvincula relações por meio da alienação. Na prática da ciência voltada para o seu desenvolvimento, permanece no centro a ideia de controle, no qual administradores e especialistas cooperam para manipular pessoas e plantas, e a separação entre sujeito (sempre humanos) e objetos (não humanos ou humanos objetificados) é constantemente reificada. Porém, o dinamismo da vida evita que a escalabilidade pretendida na plantation cumpra seus objetivos por completo, de modo que as contingências da história fazem sempre seus projetos enfrentar adversidades não esperadas (2019, p. 182).

O Antropoceno nos conduz a prestar atenção nas pragas e observar a vida em lugares desmantelados, de modo que as plantations se apresentam como lugares propícios para verificar esse tipo de acontecimento, pois suas ecologias favorecem a proliferação na forma de pragas, doenças e poluição (2019, p. 226). Com efeito, a virulência é um fato comum nas monoculturas, pois seu design propicia a emergência de organismos patogênicos (2019, p. 211).

Relações sociais estabelecidas com pragas é um tema constante nos artigos de Tsing. Uma fazenda de porcos na Dinamarca e os contínuos procedimentos para impedir a emergência de vírus; a tentativa frustrada de produzir uma monocultura de seringa no meio da floresta amazônica; a morte dos freixos na Europa ocasionada pelo comércio global de viveiros; uma paisagem abandonada pela indústria na Jutlândia; todos esses casos nos apresentam tanto efeitos não intencionais de processos de modernização quanto fracassos de projetos humanos ocasionados pela força oculta das patologias que insistem em desestabilizar as tentativas de controle do Homem. Por certo, "a história do Antropoceno não é de maneira alguma uma história da maestria humana, é uma história de consequências não intencionais e decadência” [tradução nossa] (Bubandt, 2016, p. 545).

O mundo visto pelos olhos de Anna Tsing é vivo, povoado de histórias maravilhosas. Nos artigos apresentados em seu livro, ela nos convida a prestar atenção em todos os organismos dispostos na paisagem e propõe uma antropologia renovada, tecida em um encontro com as ciências naturais. Assembleias e coordena-
10 O vínculo entre esses dois sistemas de produção já foi notado anteriormente, segundo Lévi-Strauss: "A tese é avançada com perfeita clareza n'O Capital, livro primeiro, tomo III, capítulo 31: a origem do regime capitalista remonta à descoberta de regiões auríferas e argentíferas da América, e posterior redução dos indígenas à escravidão, seguidas da conquista e pilhagem das Índias Orientais e, finalmente, da transformação da África numa "espécie de reserva comercial para a caça aos peles-negras". "Eis aí os procedimentos idílicos de acumulação primitiva que assinalam o alvorecer da era capitalista". Logo em seguida deflagra-se a guerra mercantil. "A escravidão dissimulada dos assalariados da Europa exigia como pedestal a escravidão escancarada do Novo Mundo"” (Lévi-Strauss, 1973[2017]: 329). Em crítica posterior à tese da acumulação primitiva, Rosa Luxemburgo avança neste tópico, descrevendo como no processo de acumulação do capital, este empreende uma luta constante contra a economia natural (Luxemburgo, 1913[1970], p. 317-333) - para uma releitura contemporânea das reflexões de Luxemburgo ver Almeida (2016). 
ções estão em todo e qualquer lugar, assim como a devastação que se expande e prolifera como um câncer em todo o globo. Prestar atenção nos movimentos de destruição e regeneração é uma necessidade para quem pratica antropologia no Antropoceno, pois se há algo que este novo tempo nos coloca, é a urgente mudança de paradigmas tanto no plano das teorias como no de nossas práticas.

Recebido: 09/03/2020

Aprovado: 22/06/2020 
Gabriel Holliver

\section{Referências}

ALMEIDA, Mauro Willian Barbosa de. Caipora e outros conflitos ontológicos. Revista de Antropologia da UFSCar, v. 5, p. 7-28, 2013.

ALMEIDA, Mauro Willian Barbosa de. Desenvolvimento entrópico e a alternativa da diversidade. RURIS - Revista do Centro de Estudos Rurais - UNICAMP, v. 10, n. 1, p. 19-39, 2016.

BALÉE, William L. Cultural forests of the Amazon: a historical ecology of people and their landscapes. Tuscaloosa: University of Alabama Press, 2013.

CALLON, Michel. Éléments pour une sociologie de la traduction: la domestication des coquilles Saint-Jacques et des marins-pêcheurs dans la baie de Saint-Brieuc. L'Année sociologique (1940/1948), v. 36, p. 169-208, 1986.

CHAKRABARTY, Dispesh. 2009. The climate of history: four theses. Critical Inquiry, n. 35, p. 97-222, 2009.

CLASTRES, Pierre. Entre silence et dialogue. L'Arc, numéro spécial consacré à Claude Lévi-Strauss, p. 76-78, 1968.

CLIFFORD, James; MARCUS, George E. (Eds.). Writing culture: the poetics and politics of ethnography. California: University of California Press, 1986.

DIAS, Jamille Pinheiro; VANZOLINI, Marina; SZTUTMAN, Renato; MARRAS, Stelio, BORBA, Maria; SCHAVELZON, Salvador. Uma ciência triste é aquela em que não se dança Conversações com Isabelle Stengers. Revista de Antropologia, v. 59, n. 2, p. 155-186, 2016.

GAN, Elaine. 2016. Time machines: making and unmaking rice. Tese (Doutorado em Film and Digital Media) - University of California, Santa Cruz, 2016.

GAN, Elaine; TSING, Anna. How things hold: a diagram of coordination in a Satoyama forest. Social Analysis, v. 62, n. 4, p. 102-145, 2018.

GILBERT, Scott F.; SAPP, Jan; TAUBER, Alfred I. A symbiotic view of life: we have never been individuals. The Quarterly Review of Biology, v. 87, n. 4, p. 325-341, 2012.

HARAWAY, Donna J. O manifesto das espécies de companhia: cães, pessoas e a outridade significante. Trad. de Sandra Michelli da Costa Gomes. Chicago: Prickly Paradigm Press, 2003.

HARAWAY, Donna. Antropoceno, Capitaloceno, Plantationoceno, Chthuluceno: fazendo parentes. ClimaCom Cultura Científica - pesquisa, jornalismo e arte I, ano 3, n. 5, abr. 2016.

HARAWAY, Donna. Saberes localizados: a questão da ciência para o feminismo e o privilégio da perspectiva parcial. Cadernos Pagu, n. 5, p. 7-41, 1995.

HARAWAY, Donna. The promises of monsters: a regenerative politics for inappropriate/d others. In: GROSSBERG, Lawrence; NELSON, Cary; TREICHLER, Paula A. (Eds.). Cultural Studies. New York: Routledge, 1992. p. 295-337.

HARAWAY, Donna. When species meet. Minneapolis: University of Minnesota Press, 2007.

HARAWAY, Donna; ISHIKAWA, Noboru; GILBERT, Scott F.; TSING, Anna; BUBANDT, Nils. Anthropologists are talking - about the Anthropocene. Ethnos, v. 81, n. 3, p. 535-564, 2016.

INGOLD, Tim. Perception of the environment: essays in livelihood, dwelling and skill.

London: Routledge, 2011. 
Gabriel Holliver

KOHN, Eduardo. How forests think: toward and anthropology beyond the human. Berkeley: University of California Press, 2013.

KOLBERT, Elizabeth. A sexta extinção: uma história não natural. Trad. de Mauro Pinheiro. Rio de Janeiro: Intrínseca, 2015.

LATOUR, Bruno. Reassembling the social: an introduction to actor-network theory. Oxford: Oxford University Press, 2005.

LATOUR, Bruno; STENGERS, Isabelle; TSING, Anna; BUBANDT, Nils. Anthropologists are talking - about Capitalism, Ecology, and Apocalypse. Ethnos, v. 83, n. 3, p. 587-606, 2018.

LÉVI-STRAUSS, Claude. Antropologia estrutural dois. São Paulo: Ubu, 2017 [1973].

LÉVI-STRAUSS, Claude. Antropologia estrutural. Rio de Janeiro: Tempo Brasileiro, 1958 [1975].

LIMA, Tânia Stolze. O dois e seu múltiplo: reflexões sobre o perspectivismo em uma cosmologia tupi. Mana, v. 2, n. 2, p. 21-47, 1996.

LOVELOCK, James. A Terra como um organismo vivo. In: WILSON, Edward O. (Org.). Biodiversidade. Rio de Janeiro: Nova Fronteira, 1997. p. 619-623.

LUXEMBURGO, Rosa. A acumulação do Capital: estudo sobre a Interpretação Econômica do Imperialismo. Rio de Janeiro: Zahar, 1970 [1913].

MARGULIS, Lynn. O planeta simbiótico: uma nova perspectiva da evolução. Rio de Janeiro: Rocco, 2001.

PESSOA, Fernando. O Guardador de Rebanhos. In: Poemas de Alberto Caeiro. (Nota explicativa e notas de João Gaspar Simões e Luiz de Montalvor.) Lisboa: Ática, 1993 [1946].

RAFFLES, Hugh. Insectopedia. New York: Vintage, 2010.

ROSE, Deborah Bird. Slowly: writing into the Anthropocene. TEXT, n. esp., v. 20, p. 1-14, 2013.

SNOW, Charles Percy. The two cultures. London: Cambridge University Press, 2001 [1959].

STÉPANOFF, Charles. The rise of reindeer pastoralism in Northern Eurasia: human and animal motivations entangled. Journal of the Royal Anthropological Institute, n. 23, p. 376-397, 2017.

STRATHERN, Marilyn. An awkward relationship: the case of feminism and antropology. Signs, v. 12, n. 2, p. 276-292, 1987.

STRATHERN, Marilyn. Fora de contexto: as ficções persuasivas da antropologia. In: 0 efeito etnográfico. Trad. de Iracema Dullei, Jamille Pinheiro e Luísa Valentini. São Paulo: Cosac Naify, 2014.

STRATHERN, Marilyn. Revolvendo as raízes da antropologia. Revista de Antropologia, v. 59, n. 1, p. 224-25, 2016.

STRATHERN, Marilyn. The gender of the gift: problems with women and problems with society in Melanesia. Berkeley: University of California Press, 1988.

TSING, Anna. A multispecies ontological turn? In: OMURA, Kei'ichi; MASASHI, Cho Shun No; MASAHIKO, Cho Kusumi (Eds.). The world multiple: the quotidian politics of knowing and generating entangled worlds. New York: Routledge, 2018a. p. 233-247. 
TSING, Anna. Fricção (Atrito). Trad. de Letícia Cesarino. Blog do Sociofilo. 2018b [2012]. Disponivel em: https://blogdosociofilo.com/2018/11/12/verbete-friccao-atrito-por-anna-tsing/. Acesso em: 20 abr. 2019.

TSING, Anna. The Mushroom at the end of the world: on the possibility of life in capitalist ruins. Princeton: Princeton University Press, 2015.

TSING, Anna; SWANSON, Heather; GAN, Elaine Gan; BUBANDT, Nils (Eds.). Arts of living on a damaged planet: ghosts and monsters of the Anthropocene. Minneapolis: University of Minnesota Press, 2017.

TSING. Anna. Viver nas ruínas: paisagens multiespécies no antropoceno. Thiago Mota Cardoso, Rafael Victorino Devos. Brasília: IEB Mil Folhas, 2019.

VAN DOOREN, Thom; KIRKSEY, Eben; MÜNSTER, Ursula. Estudos multiespécies: cultivando artes de atentividade. Trad. de Susana Oliveira Dias. ClimaCom Cultura Científica - pesquisa, jornalismo e arte I, Campinas, ano 3, n. 5, p. 39-66, dez. 2016.

VAN DOOREN, Thom; ROSE, Deborah Bird. Lively ethography: storying animist worlds. Environmental Humanities, v. 8, n. 1, p. 77-94. 2016.

VIVEIROS DE CASTRO, Eduardo. And. Manchester Papers in Social Anthropology, n. 7, p. 1-20, 2003.

VIVEIROS DE CASTRO, Eduardo. Métaphysiques cannibales. Lignes d'anthropologie post-structurale. Paris: PUF, 2009.

VIVEIROS DE CASTRO, Eduardo. O Nativo Relativo. Mana, Rio de Janeiro, v. 8, n. 1, p. 113148, abr. 2002.

VIVEIROS DE CASTRO, Eduardo. On models and examples: engineers and bricoleurs in the Anthropocene. Current Anthropology, v. 60, n. S20, p. S000-S000, 2019. 